Article

\title{
Rare-Earth Metals-Doped Nickel Aluminate Spinels for Photocatalytic Degradation of Organic Pollutants
}

\author{
Elzbieta Regulska * ${ }^{D}$, Joanna Breczko, Anna Basa ${ }^{(\mathbb{D})}$ and Alina Teresa Dubis $(\mathbb{D}$ \\ Faculty of Chemistry, University of Bialystok, Ciolkowskiego 1K, 15-245 Bialystok, Poland; \\ j.luszczyn@uwb.edu.pl (J.B.); abasa@uwb.edu.pl (A.B.); alina@uwb.edu.pl (A.T.D.) \\ * Correspondence: e.regulska@uwb.edu.pl
}

Received: 13 July 2020; Accepted: 29 August 2020; Published: 2 September 2020

check for updates

\begin{abstract}
Visible-light-activated photocatalysts based on samarium-doped, europium-doped, and gadolinium-doped nickel aluminates (SmNA, EuNA, GdNA) were synthesized. The spinel crystalline structures of the doped mixed metal oxides were demonstrated by X-ray diffraction (XRD) and transmission electron microscopy (TEM) analysis. The presence of the rare-earth metals (REMs) was confirmed by the energy-dispersive X-ray (EDX) studies. Ultraviolet-visible-near-infrared (UV-Vis-NIR) spectra revealed that the REMs-doped catalysts absorb in the full solar spectrum range covering both visible and near infrared wavelengths. Scanning electron microscopy (SEM) visualized the profound morphological alterations of the doped nickel aluminate samples. Consequently, the pore volume and the Brunauer-Emmett-Teller (BET) surface area decreased, while nanoparticles sizes increased. Fourier-transform infrared spectroscopy (FTIR) exposed that surfaces of REMs-doped nickel aluminates are rich in hydroxyl groups. Finally, the photocatalytic performance was notably increased through doping nickel aluminate (NA) with REMs; the highest activity was observed for EuNA.
\end{abstract}

Keywords: doped semiconductors; nickel aluminate; photocatalysis; spinel; rare-earth metals

\section{Introduction}

New routes for environmental remediation are highly coveted. Among the most effective ones that are advanced oxidation processes, heterogeneous photocatalysis (HP) demonstrates the greatest potential. The inorganic semiconductors that can utilize sunlight, a renewable source of energy, make HP both effective and economically attractive. HP has been already successfully employed for removal of pesticides [1], dyes [2-7], plastics [8], pharmaceuticals [9-11], toxic compounds [12], and many others. Its practical utility in the remediation of drinking water [13], river water [7,9], sea water [14], wastewater [7], and hospital effluents [15] was also demonstrated.

The rare-earth metals have been already proposed as dopants for spinel double oxides other than nickel aluminate. The first report dates back to 2001 when magnetic properties of $\mathrm{CoFe}_{2} \mathrm{O}_{4}$ doped with series of lanthanide ions (Ce, Sm, Eu, Gd, Dy, Er) were studied [16]. Shortly afterwards, magnesium titanium ferrites doped with $\mathrm{Nd}, \mathrm{Gd}$, and La were prepared [17]. In 2005, Peng et al. proposed Sm-doped $\mathrm{LiMn}_{2} \mathrm{O}_{4}$ as a cathode material for lithium-ion batteries [18]. The subsequent report was in 2011 when another spinel structured double oxide, i.e., cobalt-nickel aluminate doped with $\mathrm{Ce}, \mathrm{Pr}$, and $\mathrm{Sm}$, was reported as a catalyst for $\mathrm{CH}_{4}$ dry reforming [19]. Subsequently few reports on Eu- [20-22] and La-doped $\mathrm{ZnAl}_{2} \mathrm{O}_{4}$ [23] were presented. Additionally, magnesium, copper, and strontium aluminates were doped with lanthanide ions. $\mathrm{Eu}$ [24,25], $\mathrm{Yb}$, and $\mathrm{Er}$ [26] were doped into manganese aluminate; Sm was incorporated into copper aluminate [27]; and Er and $\mathrm{Yb}$ were doped into strontium aluminate [28]. Additionally, iron oxide of the spinel structure was doped with lanthanide ions, i.e., $\mathrm{Sm}, \mathrm{Eu}$, and $\mathrm{Gd}$, to boost the magnetic behavior [29]. Akhtar et al. stated that Pr-doped copper 
spinel ferrite can be a suitable material for the use in microwave and memory devices and for high frequency applications [30]. Although reports on REMs-doped spinel ferrites concentrated on their magnetic performances [16,29,30], Ahmed et al. pointed REMs-doped spinel ferrites to be attractive adsorbents for colored wastewater treatment [31]. The La-doped zinc aluminate spinel revealed catalytic activity towards transesterification reaction [23]. On the other hand, Eu- and Tb-doped zinc aluminates were demonstrated to be potential markers for gunshot residues [21]. A few more spinel aluminates were applied as phosphors $[22,24,28]$. The only one report on the REM-doped spinels refers to their photocatalytic potential [27]. Gholami and Maddahfar synthesized Sm-doped $\mathrm{CuAl}_{2} \mathrm{O}_{4}$ and examined its photocatalytic activity against methyl orange decomposition upon UV irradiation.

To the best of our knowledge, no reports on $\mathrm{Sm}$, Eu, and Gd-doped nickel aluminates are known. Additionally, only few articles on transition metal-doped nickel aluminates have been published until now. The Ru-doped nickel aluminate spinel was employed for carbon monoxide methanation [32], while $\mathrm{Nb}$-doped $\mathrm{NiAl}_{2} \mathrm{O}_{4}$ served as a catalyst of oxidative n-octane dehydrogenation [33]. The two other reports presented the enhancement of the $\mathrm{NiAl}_{2} \mathrm{O}_{4}$ photocatalytic activity after its doping with copper [34], cobalt [35], zinc [35], and manganese [35]. The photocatalytic performance was examined towards Congo Red [34], methylene blue [35], and methyl orange [35] degradation upon irradiation with visible [34] and ultraviolet light [35].

Herein, we present the first report on $\mathrm{Sm}, \mathrm{Eu}$, and $\mathrm{Gd}$-doped nickel aluminates, including their physicochemical characterization, and most importantly, we demonstrate their enhanced photocatalytic activity.

\section{Results and Discussion}

\subsection{Structural and Morphological Study}

The phases and structures of the prepared pristine and REM-doped nickel aluminate (NA) were examined by powder $\mathrm{X}$-ray diffraction. The XRD diffractograms of spinel $\mathrm{NiAl}_{2} \mathrm{O}_{4}$ (JCPDS 10-0339), $\gamma-\mathrm{Al}_{2} \mathrm{O}_{3}$ (JCPDS 50-0741) and $\mathrm{NiO}$ (JCPDS 89-7131) were included for comparison. As depicted in Figure 1, NA presents a spinel structure; its diffraction pattern coincides with the spinel nickel aluminate $\mathrm{NiAl}_{2} \mathrm{O}_{4}$ as (111), (220), (311), (400), (511), and (440) crystallographic planes are represented by the peaks at $2 \theta$ values of $19.1,31.4,37.0,45.0,59.7$, and 65.5 [36]. The corresponding reflections are also present in the patterns registered for SmNA, EuNA, and GdNA, and thus the latter exhibit spinel nickel aluminate structure as well. Additionally, we observed the diffraction patterns arising from the $\mathrm{NiO}$ phase. The latter occur at the $2 \theta$ values of $37.2,43.3$, and 62.8 and correspond to (111), (200), and (220) planes, respectively [37]. The additional contribution of the cubic $\mathrm{NiO}$ is present in both pristine and in the doped NA samples. Nevertheless, the lowest content of the $\mathrm{NiO}$ phase is present in SmNA, and is increasing in the following order SmNA $<$ NA $<$ GdNA $<$ EuNA. Additionally, the XRD peak widths revealed the small sizes of the crystallites of all the prepared samples; further confirmed by TEM studies.

The Tauc plots depicted in Figure 2a allowed us to compare the energy of inner electron transitions present in the pristine nickel aluminate and in the REM-doped catalysts. Indeed, we observed multiple linear zones, which point to the series of transitions arising from possible rotational and vibrational changes, fluorescence, phosphorescence, and the presence of trapping sites. The extrapolation of the linear parts of the Tauc plots in the low energy region revealed the pronounced difference of the pristine nickel aluminate band gap and the REM-doped semiconductor samples. While the least energetic transition for NA corresponds to $1.70 \mathrm{eV}$, the transitions of the REM-doped NA range from 0.42 for SmNA and $0.39 \mathrm{eV}$ for EuNA to $0.30 \mathrm{eV}$ for GdNA (Table 1). Therefore, incorporation of the rare-earth metal cations into the inorganic framework contributed to the significant decrease of the transition energy reaching the NIR solar spectrum range. The UV-Vis-NIR reflectance spectra confirmed the nickel aluminate spinel structure of the prepared catalysts (Figure S1). The band maximizing at $366 \mathrm{~nm}$ arises from both LMCT (ligand-to-metal charge transfer) and octahedral $\mathrm{Ni}(\mathrm{II}) 3 \mathrm{~A}_{2 \mathrm{~g}}-3 \mathrm{~T}_{1 \mathrm{~g}}$ 
transitions [38-40]. The octahedrally coordinated $\mathrm{Ni}(\mathrm{II})$ species are also manifested through the bands at 518 and $675 \mathrm{~nm}$ [41]. In turn, shoulders occurring at 580 and $617 \mathrm{~nm}$ arise from the tetrahedrally coordinated $\mathrm{Ni}$ (II) ions. Upon NA doping with the REMs cations the bands attributed to the $\mathrm{O}_{\mathrm{h}} \mathrm{Ni}$ (II) appeared to decrease, while those assigned to $\mathrm{T}_{h} \mathrm{Ni}(\mathrm{II})$ slightly increased. Therefore, we demonstrated that $\mathrm{Sm}(\mathrm{III}), \mathrm{Eu}(\mathrm{III})$, and $\mathrm{Gd}(\mathrm{III})$ cations preferred to be octahedrally coordinated.

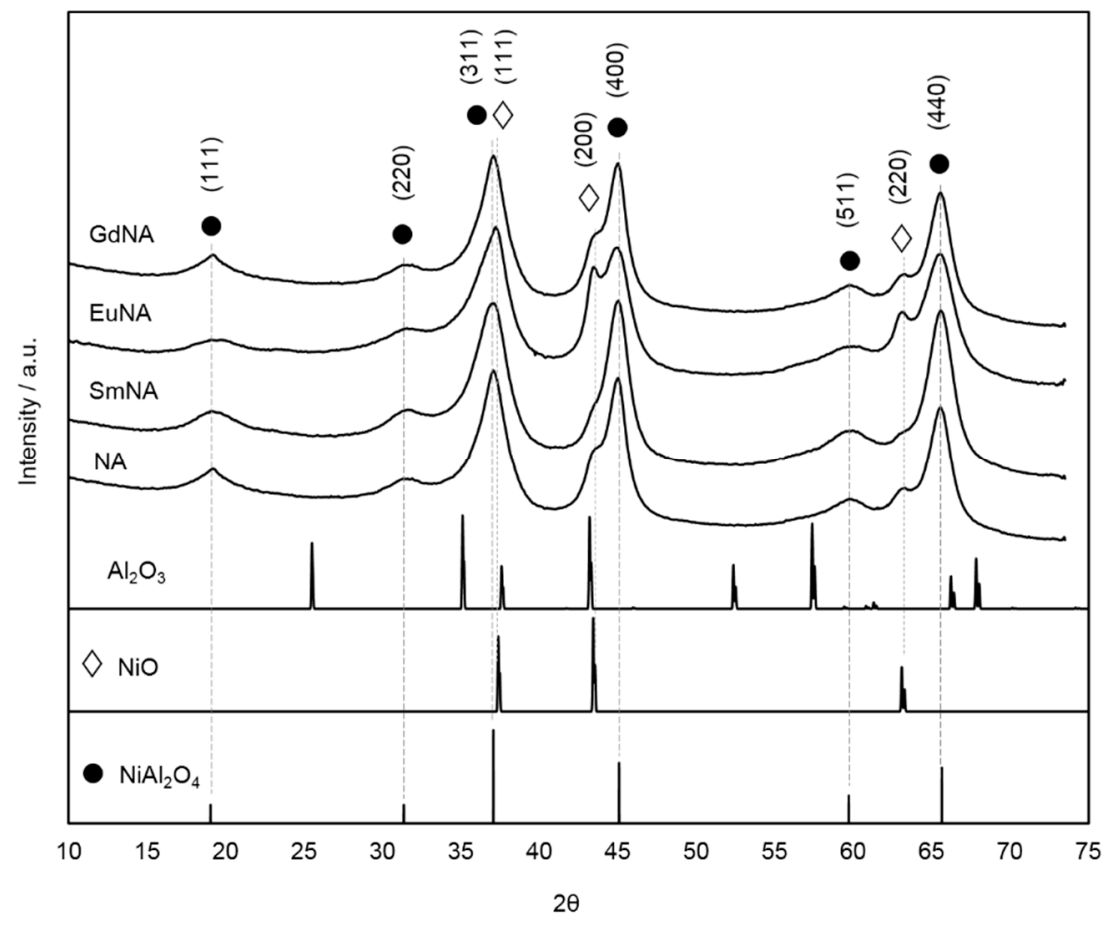

Figure 1. XRD patterns of NA, SmNA, EuNA, and GdNA.

a

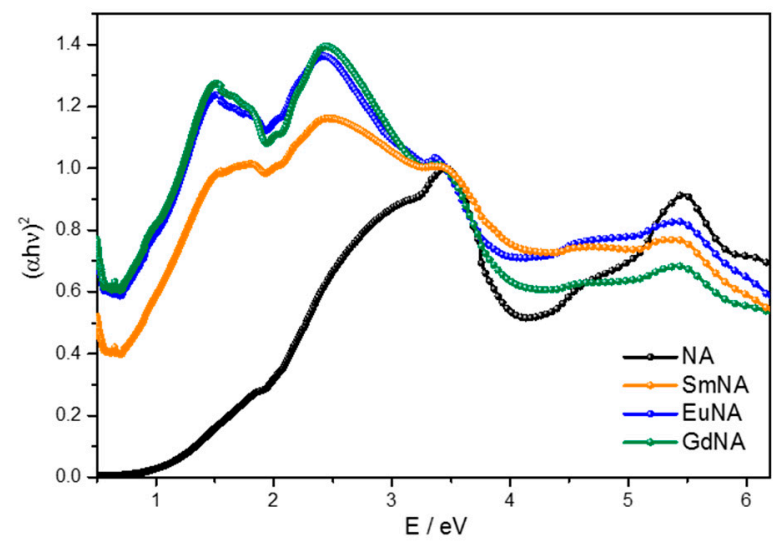

b

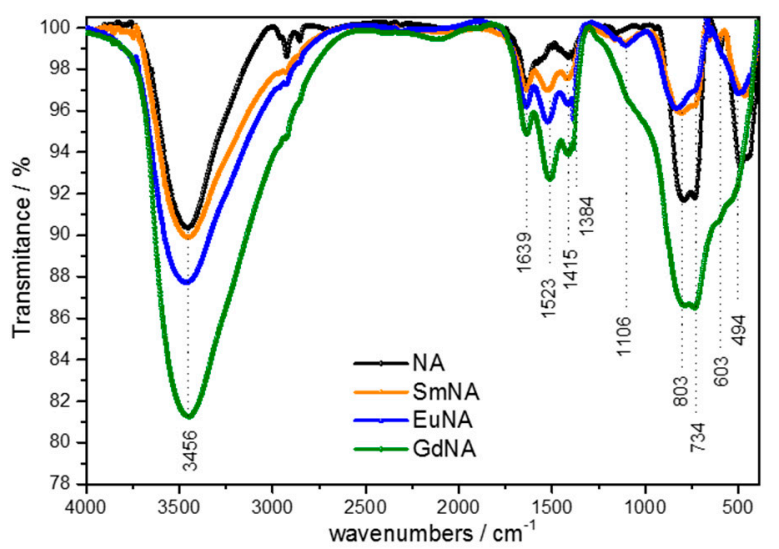

Figure 2. The Tauc plots (a) and FTIR spectra (b) of NA, SmNA, EuNA, and GdNA. 
Table 1. Summary of surface area, pore diameter, pore volume, nanoparticle size, and transition energies of NA, SmNA, EuNA, GdNA and previously reported nickel aluminates.

\begin{tabular}{ccccccc}
\hline Sample & BET $\left(\mathbf{m}^{\mathbf{2}} \mathbf{g}^{-\mathbf{1}}\right)$ & $\begin{array}{c}\text { Pore Diameter } \\
(\mathbf{n m}) \mathbf{( B E T )}\end{array}$ & $\begin{array}{c}\text { Pore Volume } \\
\left(\mathbf{c m}^{\mathbf{3}} \mathbf{g}^{-\mathbf{1}} \mathbf{)}\right.\end{array}$ & $\begin{array}{c}\text { Nanoparticle } \\
\text { Size }(\mathbf{n m})\end{array}$ & $\begin{array}{c}\text { Transition } \\
\text { Energy }(\mathbf{e V})\end{array}$ & Reference \\
\hline NA & 13.9 & 3.9 & 0.013 & 432 & 1.70 & This work \\
SmNA & 9.7 & 2.7 & 0.007 & 620 & 0.42 & This work \\
EuNA & 11.1 & 7.5 & 0.021 & 541 & 0.39 & This work \\
GdNA & 6.9 & 4.8 & 0.008 & 872 & 0.30 & This work \\
$\mathbf{N i A l}_{\mathbf{2}} \mathbf{O}_{\mathbf{4}}$ & 6.9 & 15.3 & 0.015 & - & 1.84 & {$[39]$} \\
$\mathbf{N i A l}_{\mathbf{2}} \mathbf{O}_{\mathbf{4}}$ & 17 & 10.4 & 0.040 & - & - & {$[33]$} \\
\hline
\end{tabular}

The FTIR spectroscopy analysis allowed us to prove the spinel nickel aluminate structure of the prepared materials and to investigate the presence of the functional groups on the catalysts' surfaces (see Figure $2 b$ ). The pristine and REM-doped nickel aluminates possessed the intense and broad bands with maxima at $3456 \mathrm{~cm}^{-1}$. The latter demonstrated the presence of a considerable amount of hydroxyl groups-an attractive feature of photocatalysts [42,43]. Furthermore, the bands which occurred at $1639 \mathrm{~cm}^{-1}$ arose from the H-O-H deformation vibrations of water molecules. Since the calcination of the catalysts underwent at $800{ }^{\circ} \mathrm{C}$, and thus water should have been eliminated, we attributed the presence of the adsorbed water molecules to the absorption from the atmosphere during the IR pellets formation [44,45]. Importantly, all samples revealed the bands in the 400-1000 spectrum range, where the characteristic metal-oxygen stretching vibrations from the inorganic framework were expected. Indeed, we observed the vibrational modes for $\mathrm{Ni}-\mathrm{O}, \mathrm{Al}-\mathrm{O}$, and $\mathrm{Ni}-\mathrm{O}-\mathrm{Al}$ bonds, i.e., at 494 , 603,734 , and $803 \mathrm{~cm}^{-1}$, respectively. The bands at 494 and $734 \mathrm{~cm}^{-1}$ we assigned to the octahedral $\left(\mathrm{O}_{\mathrm{h}}\right)$ and tetrahedral $\left(\mathrm{T}_{\mathrm{h}}\right)$ coordinated metal-oxygen bonds, respectively $[38,46]$. Additionally, the bands occurring at 1415 and $1523 \mathrm{~cm}^{-1}$ arose from the stretching vibrational modes associated with Al-OH bonds [46]. In turn, the band present at $1106 \mathrm{~cm}^{-1}$ we attributed to the $\mathrm{Ni}-\mathrm{OH}$ stretching vibrations [35]. Moreover, in the spectra of SmNA, EuNA, and GdNA samples the tiny N-O stretching vibrations at $1384 \mathrm{~cm}^{-1}$ arose [47]. They resulted from the residual nitrogen coming from the nitrate precursors of the rare-earth metal ions.

The TEM studies (Figure 3) pointed out that crystallite sizes were in order of nanometers. The broadest XRD peaks appeared for EuNA, which is in line with the smallest sizes of the same sample revealed by TEM analysis. The EuNA nanoparticles had a diameter of $\approx 5 \mathrm{~nm}$ and single particles can be differentiated in Figure 3(3b). Meanwhile, the nanoparticles of GdNA exhibited diameters in the range of 5-10 nm, and single particles were more difficult to distinguish. Similarly, particles of SmNA tended to aggregate and had diameters between 5 and $15 \mathrm{~nm}$. The biggest sizes of particles were demonstrated by the pristine NA, which were in the range $10-20 \mathrm{~nm}$. The d-spacing values calculated for the reflections visualized by HRTEM images (Figure 3(1c-4c)) confirmed the presence of cubic $\mathrm{NiO}\left(\mathrm{d}_{111}=0.24 \mathrm{~nm}\right)$ in the REM-doped NA with the highest content observed for EuNA. In the HRTEM images of all the prepared samples (Figure $3(1 \mathrm{c}-4 \mathrm{c})$ ) the interplanar spacing corresponding to the spinel nickel aluminate is visualized; $d_{111}=0.46 \mathrm{~nm}$.

The elemental compositions of the synthesized REM-doped materials were examined by the energy dispersive X-ray (EDX) mapping analysis (Figure 4). The presence of nickel, aluminum, and oxygen in all samples was confirmed. Moreover, the respective lanthanides were found in SmNA, EuNA, and GdNA samples. 

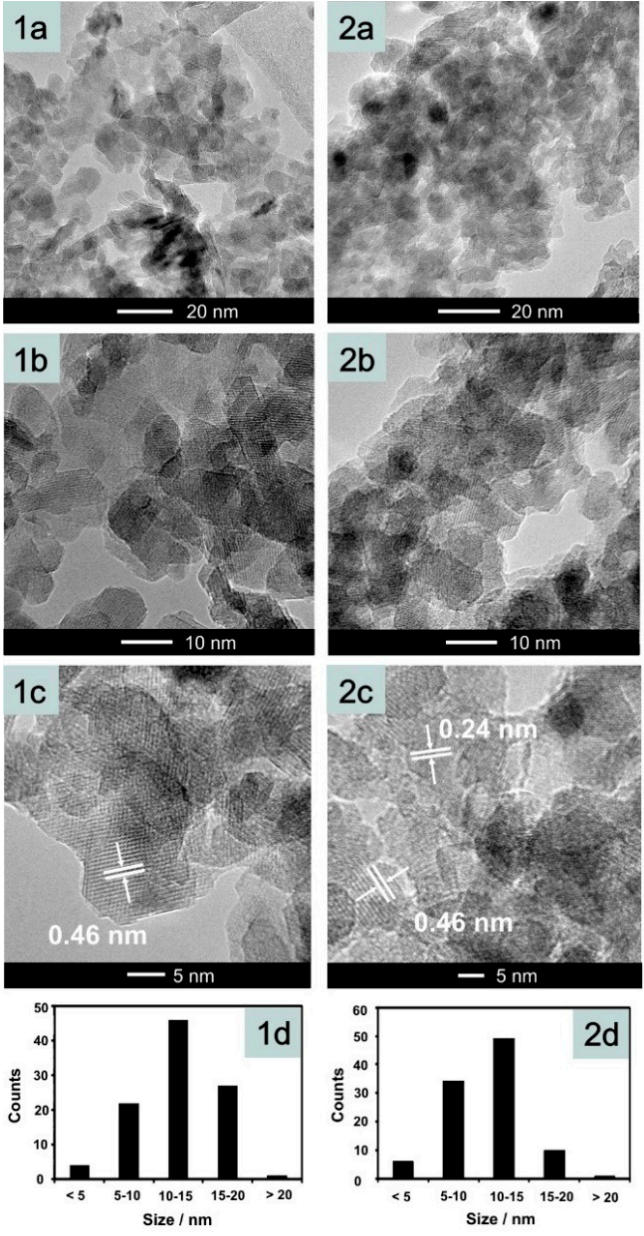
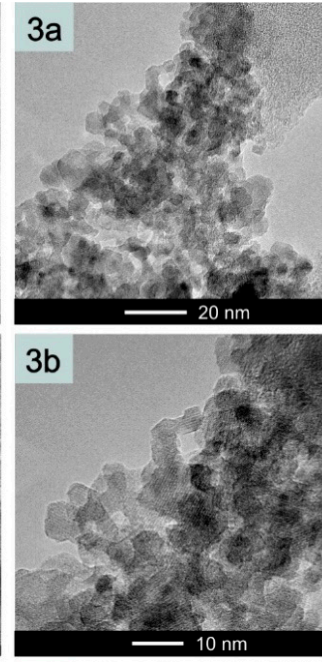
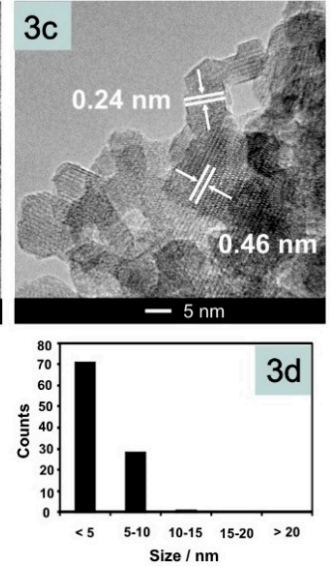
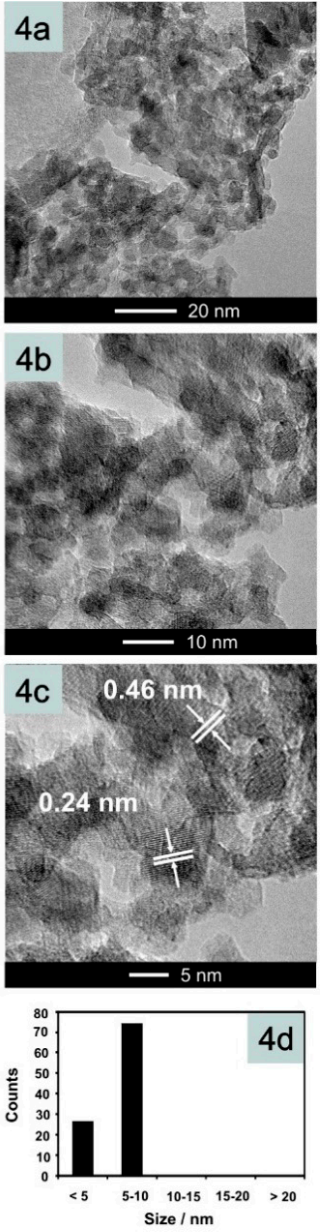

Figure 3. TEM (1a-4a,1b-4b) and HRTEM (1c-4c) images of NA (1), SmNA (2), EuNA (3), and GdNA (4). Diameter size distribution (1d-4d).
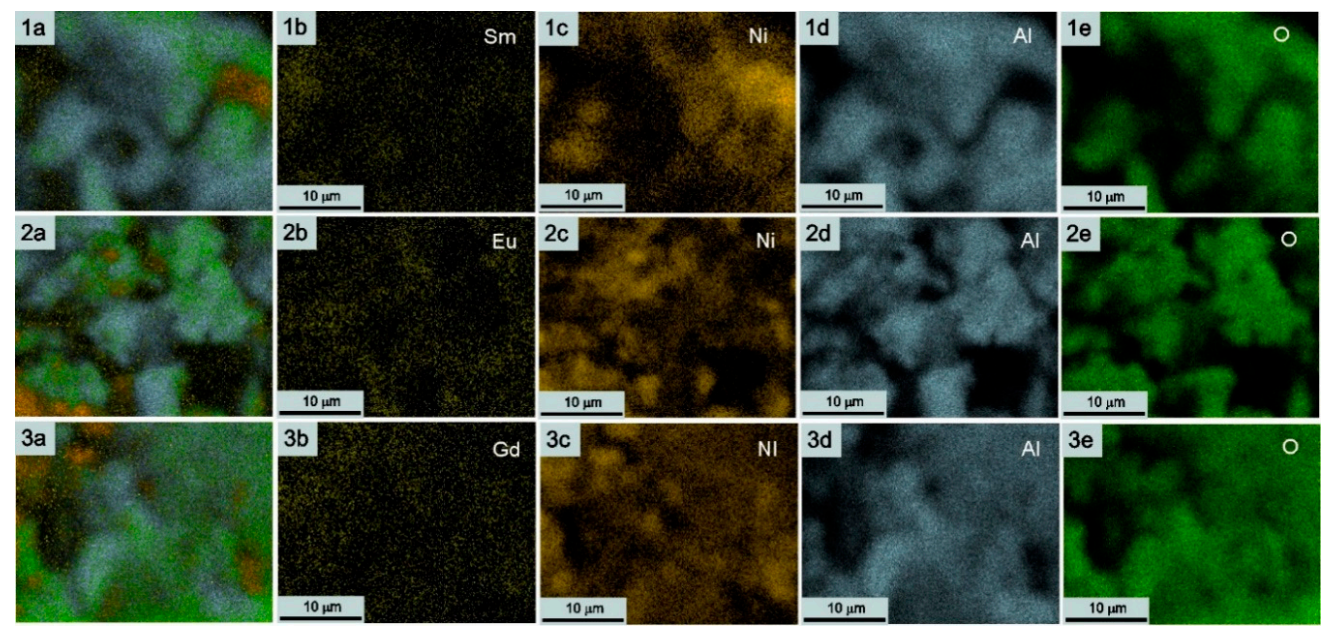

Figure 4. Energy dispersive X-ray (EDX) mapping analyses of SmNA (1a-1e), EuNA (2a-2e), and GdNA (3a-3e). REM (1b-3b), Ni (1c-3c), Al (1d-3d), O (1e-3e).

Subsequently, the morphologies were investigated using SEM technique. The images of the pristine and REM-doped NA samples are depicted in Figure 5. At the microscale, NA spinels form a compact porous sponge-like structure with many channels (Figure 5(1a-1c)). The morphology of REM-doped NA samples (Figure 5(2a-2c,3a-3c,4a-4c)) differs significantly from the morphology 
exhibited by pristine catalyst, namely, a tendency to agglomerate is observed. Separate aggregates of REM-doped NA samples can be distinguished and their sizes increase in the following order, EuNA $<$ SmNA < GdNA. The latter tendency correlates well with the sizes of nanoparticles of the respective materials derived from TEM investigations. Afterwards, this relation was corroborated by the physisorption analysis. Thus, the morphology of the reported catalysts should be translated to the specific surface area. Therefore, the nitrogen adsorption-desorption studies were performed.
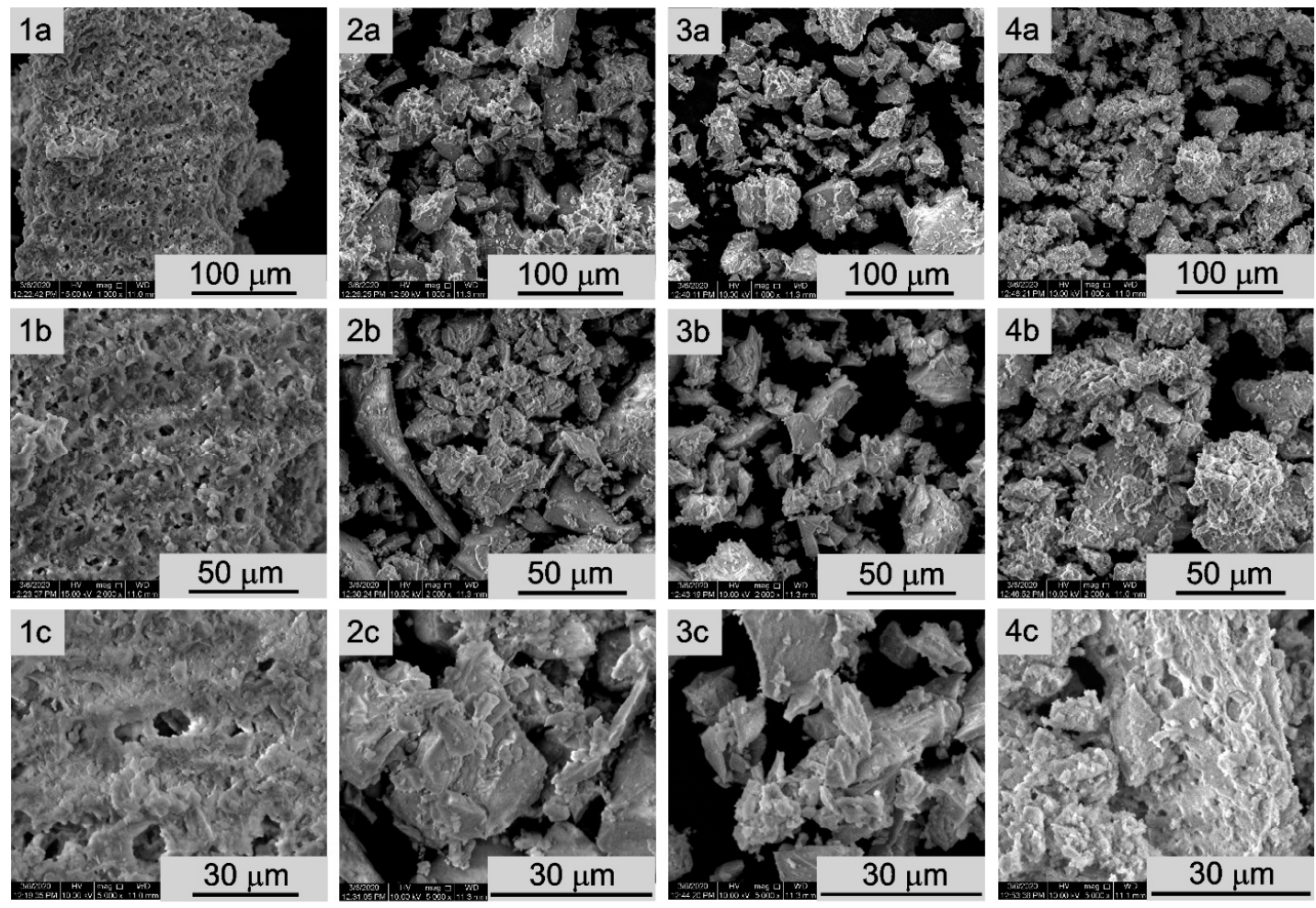

Figure 5. SEM images of the pristine NA (1a-1c), SmNA (2a-2c), EuNA (3a-3c), and GdNA (4a-4c).

The surface area estimated based on BET isotherms reached the highest value for the pristine spinel sample, $13.9 \mathrm{~m}^{2} \mathrm{~g}^{-1}$. This value was within range obtained by others, i.e., $6.9-21 \mathrm{~m}^{2} \mathrm{~g}^{-1}[33,39]$. The subsequent NA doping with the REM contributed to the decreases in BET surface area for SmNA, EuNA, and GdNA (Table 1). In fact, EuNA exhibited the highest BET surface area among all doped spinel samples; $11.1 \mathrm{~m}^{2} \mathrm{~g}^{-1}$. This value was only slightly smaller from the BET surface area of the pristine NA. In turn, GdNA exhibited a two-times smaller specific surface area of $6.9 \mathrm{~m}^{2} \mathrm{~g}^{-1}$, whereas the BET surface area of SmNA reached $9.7 \mathrm{~m}^{2} \mathrm{~g}^{-1}$. Moreover, EuNA exhibited the highest pore width and correspondingly the highest pore volume. Accordingly, SEM images showed the biggest distances between agglomerates for EuNA catalyst (Figure 5(3a-3c)). On the other hand, GdNA had the highest tendency to agglomerate as visualized by SEM studies (Figure 5(4a-4c)). Therefore, the increase in size of the doped catalyst agglomerates translated into a decrease of BET surface area. Indeed, REM cations possess high ionic radii $\left(\mathrm{Sm}^{3+}, 0.958 \AA\right.$; $\mathrm{Eu}^{3+}, 0.947 \AA$; $\mathrm{Gd}^{3+}$, $0.938 \AA$ ) [48], considerably higher with respect to $\mathrm{Ni}^{2+}(0.69 \AA)$ [48] and $\mathrm{Al}^{3+}(0.535 \AA)$ [48]. Therefore, the substitution of the nickel cations generates the defects on cationic lattice sites and additionally may force oxygen vacancies [49-51]. Consequently, the induced structural disorder is responsible for the increased particles sizes and thus smaller surface area. Similarly, the herein observed decrease of NA surface area after doping with REM aligned well with the findings of others for doped spinels. Namely, Friedrich et al. [33] demonstrated, that BET surface area of nickel aluminate decreases after doping with nobium from 17 to $8 \mathrm{~m}^{2} \mathrm{~g}^{-1}$, respectively. 


\subsection{Photocatalytic Activity Study}

The photocatalytic activities of the pristine and $\mathrm{Sm}, \mathrm{Eu}$, and $\mathrm{Gd}$-doped nickel aluminates, i.e., NA, SmNA, EuNA, and GdNA, were examined through the phenol degradation over the given photocatalyst and under the simulated visible light irradiation. The efficiency of the photocatalytic degradation was calculated according to the following formula $\eta=\left(1-C_{t} / C_{0}\right) \times 100 \%$, where $C_{0}$ and $C_{t}$ denote initial and final concentrations, respectively. The photocatalytic degradation efficiencies, together with the kinetic parameters, i.e., constant rates and the degradation half-life times, are collected in Table 2. Figure 6 a depicts the phenol degradation within $2 \mathrm{~h}$ of the irradiation over the prepared catalyst. The catalysts doped with the rare-earth metals demonstrated better photocatalytic performance with respect to the pristine spinel aluminate. The EuNA catalyst showed the highest photocatalytic activity. Phenol degradation over EuNA reached 93\%. Correspondingly, decomposition of phenol in the presence of EuNA was described by the highest rate constant $\left(0.0220 \mathrm{~min}^{-1}\right)$ and the lowest half-life time (32 $\mathrm{min}$ ) (Table 2). The photodegradation efficiency decreased from EuNA in the following order, EuNA $<$ SmNA $<$ GdNA $<$ NA. Nevertheless, the photocatalytic performances of the doped samples were similar. The SmNA and GdNA samples allowed for 90 and $89 \%$ (Table 2) of phenol degradation, respectively. Accordingly, the half-life times estimated for SmNA and GdNA reached 36 and 37 min (Table 2). On the other hand, the photocatalytic performance of the pristine NA was considerably lower compared to the rare-earth metal-doped nickel aluminates. Notably, the efficiency of the phenol degradation over pristine NA decreased to $79 \%$ (Table 2). Correspondingly, in the given conditions, rate constant and half-life time equaled $0.0136 \mathrm{~min}^{-1}$ and $51 \mathrm{~min}$ (Table 2), respectively.

Table 2. Photocatalytic degradation efficiencies $(\eta)$, first-order rate constants $(k)$, and half-life times for the phenol degradation over given catalysts (NA, SmNA, EuNA, GdNA), and upon $2 \mathrm{~h}$ of irradiation with simulated solar light.

\begin{tabular}{ccccc}
\hline Sample & Scavenger & $\boldsymbol{\eta} \mathbf{( \% )}$ & $\mathbf{k}\left(\mathbf{m i n}^{-\mathbf{1}}\right)$ & $\mathbf{t}_{\mathbf{1} / \mathbf{2}}(\mathbf{m i n})$ \\
\hline NA & - & 79 & 0.0136 & 51 \\
SmNA & - & 90 & 0.0189 & 37 \\
SmNA & $\mathrm{AO}^{1}$ & 69 & 0.0093 & 75 \\
SmNA & $\mathrm{DMSO}$ & 65 & 0.0094 & 74 \\
SmNA & $i \mathrm{PrOH}$ & 53 & 0.0061 & 114 \\
EuNA & - & 93 & 0.0220 & 32 \\
EuNA & $\mathrm{AO}^{1}$ & 43 & 0.0046 & 151 \\
EuNA & $\mathrm{DMSO}^{1}$ & 55 & 0.0066 & 105 \\
EuNA & $i \mathrm{PrOH}^{2}$ & 24 & 0.0022 & 315 \\
GdNA & - & 89 & 0.0192 & 36 \\
GdNA & $\mathrm{AO}{ }^{1}$ & 75 & 0.0112 & 62 \\
GdNA & $\mathrm{DMSO}$ & 76 & 0.0114 & 61 \\
GdNA & $i \mathrm{PrOH}$ & 65 & 0.0088 & 79 \\
\hline \multicolumn{5}{c}{ Ammonium oxalate. }
\end{tabular}

Subsequently, we examined the mechanism responsible for the enhancement of the photocatalytic performance with the REM-doped nickel aluminate samples. With this in mind, we conducted the series of photocatalytic experiments in the presence of selected scavengers. For that purpose, we employed ammonium oxalate (AO), dimethylsulfoxide (DMSO) and isopropyl alcohol ( $\mathrm{PrOH})$. Figure $6 \mathrm{~b}-\mathrm{d}$ shows that after addition of isopropyl alcohol, degradation efficiency with the presence of all REM-doped spinels decreased to the highest extent. Notably, the $\eta$ for the EuNA decreased from $93 \%$ to $24 \%$ (Table 2). As Figure $6 a$ demonstrates, EuNA showed the highest photocatalytic activity among all examined photocatalysts. Therefore, addition of isopropyl alcohol affected $\eta$ of EuNA to the highest extent. Photodegradation efficiencies of SmNA and GdNA in the presence of $i \mathrm{PrOH}$ decreased from $90 \%$ to $53 \%$ and from $89 \%$ to $65 \%$, respectively. Accordingly, we concluded that generation of hydroxyl radicals was crucial for the photocatalytic performances of REM-doped nickel aluminate catalysts (Scheme 1). Nevertheless, hydroxyl radicals may be formed with the contribution of both electron holes in valence band (VB) and electrons 
in conduction band (CB). The photocatalytic experiments conducted with the addition of AO and DMSO pointed out that hydroxyl radicals are generated at both VB and CB. As exemplified for EuNA, addition of $\mathrm{AO}$ and DMSO decreased $\eta$ by $43 \%$ and $55 \%$, respectively. On the other, applied scavengers had smaller effects on SmNA and GdNA photocatalytic performances, as they exhibited smaller activity with respect to EuNA. Thus, we hypothesized that lower amount of hydroxyl radicals was produced at their surface.
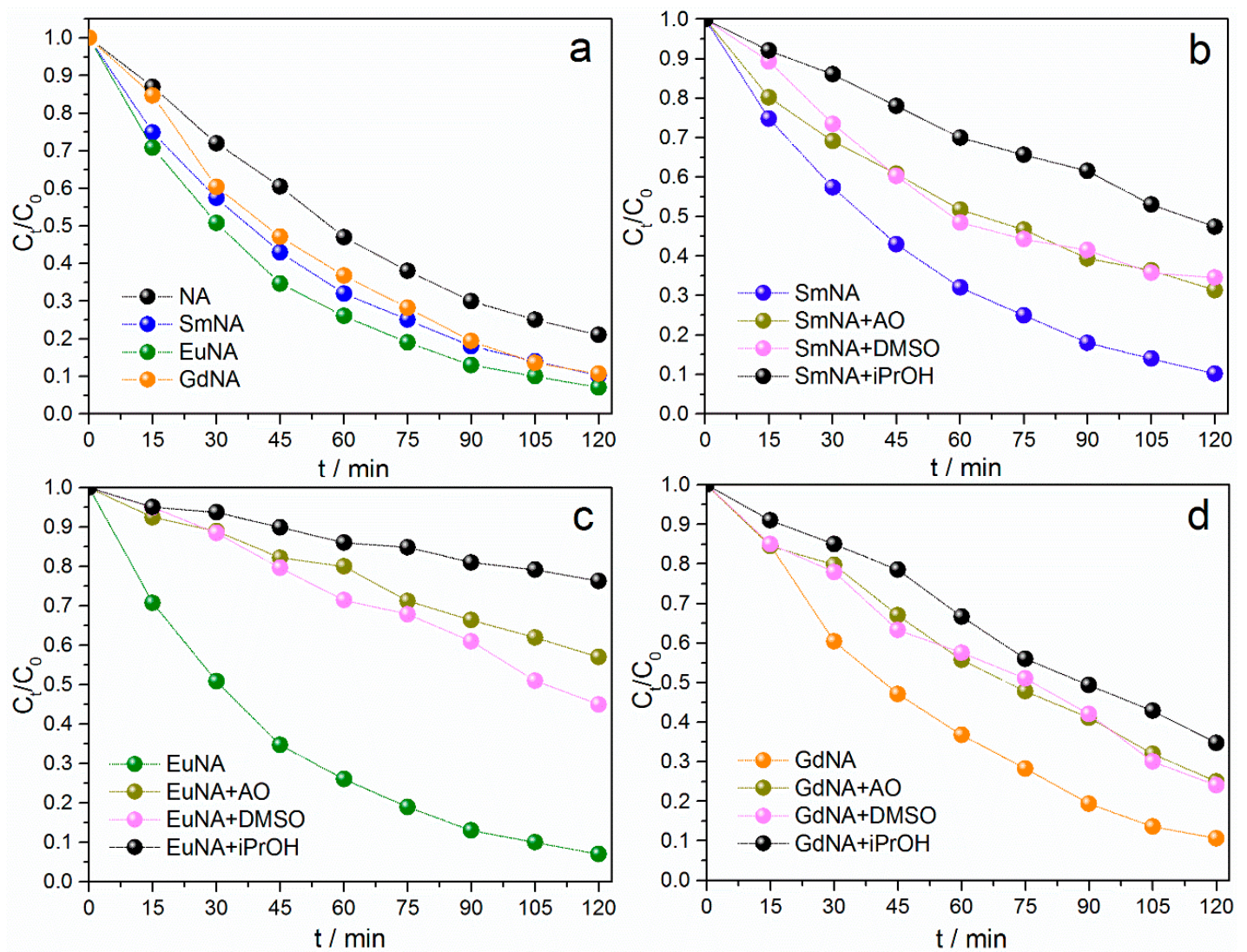

Figure 6. Photocatalytic degradation of phenol over (a) pristine NA, SmNA, EuNA, or GdNA, (b) SmNA with the presence of AO, DMSO, or iPrOH, (c) EuNA with the presence of AO, DMSO, or iPrOH, and (d) GdNA with a presence of AO, DMSO or iPrOH.

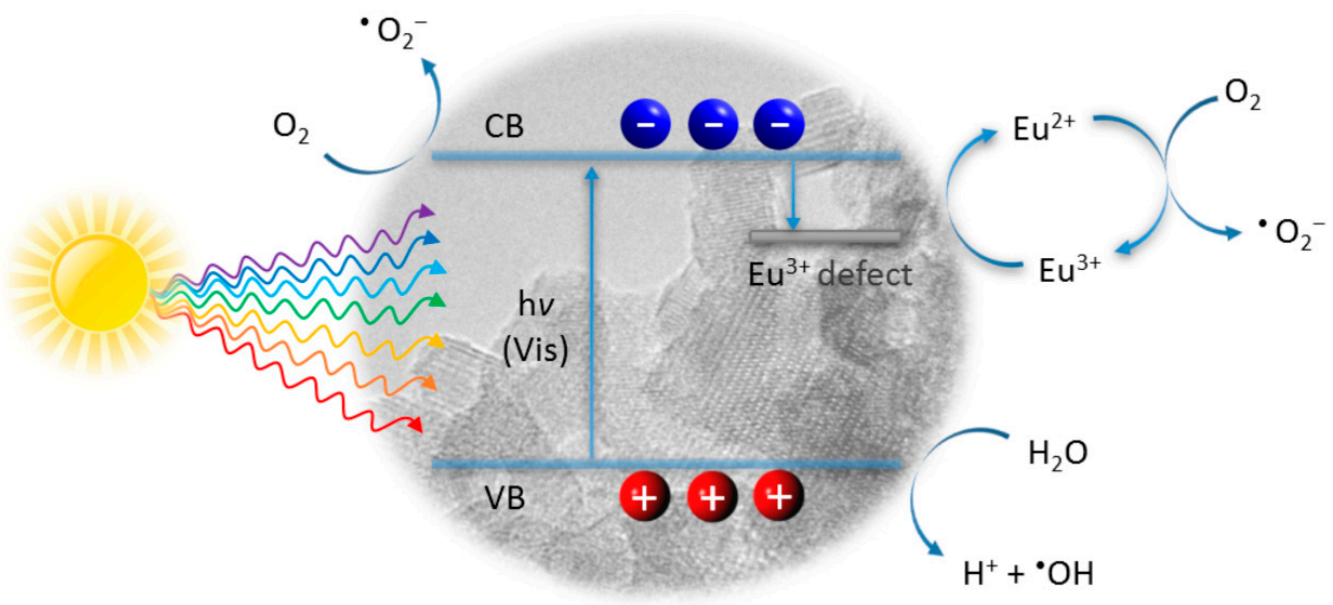

Scheme 1. Scheme of the energy levels in EuNA with reactions providing oxygen reactive species responsible for the $\mathrm{PH}$ photocatalytic degradation.

Nevertheless, all rare-earth metal-doped nickel aluminate samples revealed higher photocatalytic activity compared to the pristine NA. The trivalent cations, Sm(III), Eu(III), and Gd(III), doped 
into the nickel aluminate spinel structure, were able to harvest the electrons generated after the photocatalyst excitation. Therefore, they prevent recombination of the electron-hole pair, and thus allowed for producing the hydroxyl radicals. The latter, subsequently, led to the decomposition of the model pollutant-phenol.

\section{Materials and Methods}

\subsection{Materials}

Ammonium oxalate, aluminum nitrate nonahydrate, dimethyl sulfoxide, europium(III) nitrate pentahydrate, gadolinium(III) nitrate hexahydrate, isopropyl alcohol, nickel(II) nitrate hexahydrate, phenol, and samarium(III) nitrate hexahydrate were purchased from Sigma-Aldrich. Aqueous ammonia and sodium hydroxide were obtained from POCh (Gliwice, Poland).

\subsection{Synthetic Procedures}

\subsubsection{Synthesis of $\mathrm{NiAl}_{2} \mathrm{O}_{4}$}

Nickel aluminate catalyst was prepared by a coprecipitation method. In a typical experiment nickel and aluminum were coprecipitated from an aqueous nitrate solution $\left(5 \mathrm{mmol} \cdot \mathrm{L}^{-1}\right)$ by adding an aqueous ammonia $\left(1 \mathrm{~mol} \cdot \mathrm{L}^{-1}\right)$ solution to produce a $\mathrm{pH}$ of about 8 . The molar ratio of $\mathrm{Al} / \mathrm{Ni}$ in the solution was 2.0. The precipitates were collected by filtration, washed with water, and dried at $100^{\circ} \mathrm{C}$ for $6 \mathrm{~h}$. The as-synthesized nickel aluminate was subjected to calcination in air at $800{ }^{\circ} \mathrm{C}$ for $3 \mathrm{~h}$ to obtain the crystalline spinel, which was labeled as NA.

\subsubsection{Synthesis of $\mathrm{Sm}, \mathrm{Eu}$, and $\mathrm{Gd}-$ doped $\mathrm{NiAl}_{2} \mathrm{O}_{4}$}

The REMs-doped NA samples were prepared according to the procedure described for the synthesis of $\mathrm{NiAl}_{2} \mathrm{O}_{4}$. Additionally, the nitrate of the corresponding rare-earth metal $\left(5 \mathrm{mmol} \cdot \mathrm{L}^{-1}\right)$ was mixed with the nickel and aluminum nitrates following the 0.05:1:2 molar ratio. The obtained samples of Sm, Eu, and Gd-doped NA were labeled as SmNA, EuNA, and GdNA, respectively.

\subsection{Characterization of Photocatalysts}

The powder X-ray diffraction data were measured at 293K using a SuperNova diffractometer (Rigaku, The Woodlands, TX, USA) with a CCD detector and a Cu-K $\alpha$ radiation source at the $158 \mathrm{~mm}$ sample-to-detector distance.

Scanning electron microscopy images were recorded by secondary electron SEM with the use of an INSPECT S50 scanning electron microscope (FEI, Hillsboro, OR, USA). The accelerating voltage of the electron beam was $15 \mathrm{keV}$ and the working distance was $10 \mathrm{~mm}$. EDX TEM images were obtained by a transmission electron microscope system (FEI Teknai T20 G2 X-TWIN, Hillsboro, OR, USA), operating at $200 \mathrm{kV}$, equipped with a $\mathrm{LaB}_{6}$ source.

Diffuse reflectance UV-Vis spectra were recorded on a Jasco V-30 UV-Vis/NIR spectrophotometer (Jasco, De Meern, Netherlands) equipped with an integrating sphere $60 \mathrm{~mm}$ in diameter using $\mathrm{BaSO}_{4}$ as a reference.

Nitrogen adsorption/desorption measurements were performed using an ASAP2020 analyzer (Micromeritics Corp., Norcross, GA, USA) at liquid $\mathrm{N}_{2}$ temperature. Before the experiment all samples were degassed for $20 \mathrm{~h}$ at $130{ }^{\circ} \mathrm{C}$ under reduced pressure.

The FTIR spectra were recorded in the transmission mode in the range $400-4000 \mathrm{~cm}^{-1}$ with a Nicolet 6700 spectrometer (Thermo Scientific, Madison, WI, USA) at room temperature. The spectra were collected at a resolution $4 \mathrm{~cm}^{-1}$.

The UV-vis spectra were recorded with a HITACHI U-2800A UV-vis spectrophotometer (Hitachi, Tokyo, Japan) equipped with a double monochromator and a single beam optical system (190-700 nm). 
The SUNTEST CPS+ (ATLAS, Mount Prospect, IL, USA) solar simulator apparatus was used to perform photocatalytic degradation experiments. SUNTEST CPS+ emits irradiation in the range of $380-700 \mathrm{~nm}$.

\subsection{Photocatalysis Experiments}

The photocatalytic degradation experiments were investigated in a $50 \mathrm{~mL}$ glass cell. The SUNTEST CPS+ solar simulator apparatus was applied as the irradiation source. The photon flux of solar-simulated radiation was equal to $2.32 \times 10^{-6}$ Einstein s${ }^{-1}$ for $250 \mathrm{~W} \mathrm{~m}^{-2}$. The photocatalytic experiment was conducted under the room temperature $\left(24^{\circ} \mathrm{C}\right)$. The reaction mixture consisted of $20 \mathrm{~mL}$ of the phenol $\left(\mathrm{PH}, 10^{-4} \mathrm{~mol} \cdot \mathrm{L}^{-1}\right)$ aqueous solution and a photocatalyst $\left(1.5 \mathrm{~g} \cdot \mathrm{L}^{-1}\right)$. Prior to photocatalytic experiments, the catalyst was settled in suspension for $60 \mathrm{~min}$ in the dark for the adsorption-desorption equilibrium. All solutions were prepared using deionized water, which was obtained by Polwater apparatus (Polwater, Cracow, Poland). The photocatalytic degradation of $\mathrm{PH}$ followed pseudo-first-order kinetics; thus, the photocatalytic rate constant was determined according to the following equation: $\ln \left(C_{0} / C_{t}\right)=k t$, where $C_{0}$-initial concentration, $C_{t}$-concentration after time $\mathrm{t}, \mathrm{k}-$ kinetic rate constant, $\mathrm{t}$ - time. The half-life time, $\mathrm{t}_{1 / 2}$, was determined from the following equation: $\mathrm{t}_{1 / 2}=\ln 2 / \mathrm{k}$.

\subsection{Reactive Species Scavenging}

The generation of electron holes, hydroxyl radicals, and electrons was determined by treating the reaction suspensions with ammonium oxalate (AO), dimethyl sulfoxide (DMSO), and isopropyl alcohol (IPA) at concentrations of $0.5 \mathrm{mg} \mathrm{mL}^{-1}$ each of the respective scavengers [12]. The chemicals outlined above easily react with electron holes, free electrons, and hydroxyl radicals, respectively, and thus are known as their scavengers. The irradiation excites the semiconductor photocatalyst; hence electron holes appear in the valence band (VB), whereas free electrons are injected into the conduction band (CB). Moreover, in the aqueous environment, hydroxyl radicals are generated with the contribution of $\mathrm{VB}$ (Scheme 1). In turn, electrons injected to the CB produce the superoxide radicals, which subsequently convert into hydroxyl radicals. Thus the decrease in the photodegradation efficiency in the presence of the given scavenger can clearly indicates the importance of each radical species for the photocatalytic degradation and thus point to the mechanism, as depicted in Scheme 1.

\section{Conclusions}

Herein, we designed visible-light-activated photocatalysts by utilizing the synergism of the $\mathrm{Sm}(\mathrm{III}), \mathrm{Eu}(\mathrm{III})$, and $\mathrm{Gd}(\mathrm{III})$ ions and the spinel nickel aluminate (NA). We examined the structural and morphological features of the pristine NA and the REMs-doped NA, i.e., SmNA, EuNA, and GdNA. The introduced REMs cations allowed for the utilization of NIR solar spectrum range, while NA exploited the visible part of the sunlight. Furthermore, the incorporation of the REMs cations contributed to the decrease of the electron-hole pair recombination. As a result, we succeeded in harvesting the broad range of the solar spectrum, and moreover, in enhancing the efficiency of the photocatalytic reaction. The obtained materials presented the enhanced potential to decompose phenol, the model toxic pollutant. The EuNA showed the highest photocatalytic performance. In that manner, we demonstrated the feasibility of synthesizing the Vis-NIR-activated photocatalysts through the doping of NA with the REMs cations.

Supplementary Materials: The following are available online at http://www.mdpi.com/2073-4344/10/9/1003/s1. Figure S1. The UV-Vis-NIR absorption spectra of NA, SmNA, EuNA, and GdNA; Figure S2. Detailed particle size distribution of EuNA, (a) and GdNA (b).

Author Contributions: Conceptualization, E.R.; methodology, J.B. and E.R.; TEM and XRD investigations, A.B.; IR analysis, A.T.D. and J.B.; UV-Vis-NIR analysis, A.T.D. and J.B.; SEM analysis, E.R. and J.B.; sorption analysis, J.B.; photocatalytic studies, E.R.; writing—original draft preparation, E.R.; writing-review and editing, E.R., J.B., A.B., and A.T.D. All authors have read and agreed to the published version of the manuscript. 
Funding: This research was funded by the Polish Ministry of Science and Higher Education under subsidy granted to the Faculty of Biology and Chemistry, University of Bialystok for R\&D and related tasks aimed at development of young scientists and PhD students and for maintaining the research potential of the Faculty of Biology and Chemistry, University of Bialystok. Diffractometer, SEM, and TEM microscopes, the IR spectrometer, and the UV-vis/NIR spectrophotometer were funded by the EU, as part of the Operational Programme Development of Eastern Poland, projects POPW.01.03.00-20-034/09-00 and POPW.01.03.00-20-004/11-00.

Conflicts of Interest: The authors declare no conflict of interest.

\section{References}

1. Ahmadifard, T.; Heydari, R.; Tarrahi, M.J.; Khorramabadi, G.S. Photocatalytic Degradation of Diazinon in Aqueous Solutions Using Immobilized MgO Nanoparticles on Concrete. Int. J. Chem. React. Eng. 2019, 17. [CrossRef]

2. Regulska, E.; Małgorzata Brus, D.; Karpinska, J. Photocatalytic Decolourization of Direct Yellow 9 on Titanium and Zinc Oxides. Int. J. Photoenergy 2013, 2013, 1-9. [CrossRef]

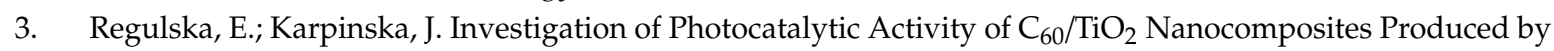
Evaporation Drying Method. Pol. J. Environ. Stud. 2014, 23, 2175-2182.

4. Sapkota, K.P.; Lee, I.; Hanif, M.; Islam, M.; Hahn, J.R. Solar-Light-Driven Efficient ZnO-Single-Walled Carbon Nanotube Photocatalyst for the Degradation of a Persistent Water Pollutant Organic Dye. Catalysts 2019, 9, 498. [CrossRef]

5. Regulska, E.; Brus, D.M.; Rodziewicz, P.; Sawicka, S.; Karpinska, J. Photocatalytic degradation of hazardous Food Yellow 13 in $\mathrm{TiO}_{2}$ and $\mathrm{ZnO}$ aqueous and river water suspensions. Catal. Today 2015, 72-81. [CrossRef]

6. Regulska, E.; Rivera-Nazario, D.M.; Karpinska, J.; Plonska-Brzezinska, M.E.; Echegoyen, L. Enhanced Photocatalytic Performance of Porphyrin/Phthalocyanine and Bis(4-pyridyl)pyrrolidinofullerene modified Titania. ChemistrySelect 2017, 2, 2462-2470. [CrossRef]

7. Regulska, E.; Rivera-Nazario, D.; Karpinska, J.; Plonska-Brzezinska, M.; Echegoyen, L. Zinc Porphyrin-Functionalized Fullerenes for the Sensitization of Titania as a Visible-Light Active Photocatalyst: River Waters and Wastewaters Remediation. Molecules 2019, 24, 1118. [CrossRef]

8. Tofa, T.S.; Kunjali, K.L.; Paul, S.; Dutta, J. Visible light photocatalytic degradation of microplastic residues with zinc oxide nanorods. Environ. Chem. Lett. 2019, 17, 1341-1346. [CrossRef]

9. Regulska, E.; Karpinska, J. Photocatalytic degradation of olanzapine in aqueous and river waters suspension of titanium dioxide. Appl. Catal. B Environ. 2012, 117, 96-104. [CrossRef]

10. Regulska, E.; Karpinska, J. Investigation of novel material for effective photodegradation of bezafibrate in aqueous samples. Environ. Sci. Pollut. Res. 2014, 21, 5242-5248. [CrossRef]

11. Fanourakis, S.K.; Peña-Bahamonde, J.; Bandara, P.C.; Rodrigues, D.F. Nano-based adsorbent and photocatalyst use for pharmaceutical contaminant removal during indirect potable water reuse. Npj Clean Water 2020, 3, 1. [CrossRef]

12. Regulska, E.; Breczko, J.; Basa, A. Pristine and Graphene-Quantum-Dots-Decorated Spinel Nickel Aluminate for Water Remediation from Dyes and Toxic Pollutants. Water 2019, 11, 953. [CrossRef]

13. Suryaman, D.; Hasegawa, K. Biological and photocatalytic treatment integrated with separation and reuse of titanium dioxide on the removal of chlorophenols in tap water. J. Hazard. Mater. 2010, 183, 490-496. [CrossRef]

14. Rubio, D.; Casanueva, J.F.; Nebot, E. Improving UV seawater disinfection with immobilized $\mathrm{TiO}_{2}$ : Study of the viability of photocatalysis $\left(\mathrm{UV} 254 / \mathrm{TiO}_{2}\right)$ as seawater disinfection technology. J. Photochem. Photobiol. Chem. 2013, 271, 16-23. [CrossRef]

15. Van Doorslaer, X.; Dewulf, J.; De Maerschalk, J.; Van Langenhove, H.; Demeestere, K. Heterogeneous photocatalysis of moxifloxacin in hospital effluent: Effect of selected matrix constituents. Chem. Eng. J. 2015, 261, 9-16. [CrossRef]

16. Kahn, M.L.; Zhang, Z.J. Synthesis and magnetic properties of $\mathrm{CoFe}_{2} \mathrm{O}_{4}$ spinel ferrite nanoparticles doped with lanthanide ions. Appl. Phys. Lett. 2001, 78, 3651-3653. [CrossRef]

17. Ahmed, M.A.; Ateia, E.; El-Dek, S.I. Spectroscopic analysis of ferrite doped with different rare earth elements. Vib. Spectrosc. 2002, 30, 69-75. [CrossRef]

18. Peng, Z.; Hu, G.; Liu, Y. Influence on performance and structure of spinel $\mathrm{LiMn}_{2} \mathrm{O}_{4}$ for lithium-ion batteries by doping rare-earth Sm. J. Cent. South Univ. Technol. 2005, 12, 28-32. [CrossRef] 
19. Foo, S.Y.; Cheng, C.K.; Nguyen, T.-H.; Adesina, A.A. Evaluation of lanthanide-group promoters on $\mathrm{Co}-\mathrm{Ni} / \mathrm{Al}_{2} \mathrm{O}_{3}$ catalysts for $\mathrm{CH}_{4}$ dry reforming. J. Mol. Catal. A Chem. 2011, 344, 28-36. [CrossRef]

20. Silva, D.; Abreu, A.; Davolos, M.R.; Rosaly, M. Determination of the local site occupancy of $\mathrm{Eu}^{3+}$ ions in $\mathrm{ZnAl}_{2} \mathrm{O}_{4}$ nanocrystalline powders. Opt. Mater. 2011, 33, 1226-1233. [CrossRef]

21. Lucena, M.A.M.; de Sá, G.F.; Rodrigues, M.O.; Alves, S.; Talhavini, M.; Weber, I.T. $\mathrm{ZnAl}_{2} \mathrm{O}_{4}$-based luminescent marker for gunshot residue identification and ammunition traceability. Anal. Methods 2013, 5, 705-709. [CrossRef]

22. Ferandez-Osorio, A.; Rivera, C.E.; Chavez, J. Europium-Doped $\mathrm{ZnAl}_{2} \mathrm{O}_{4}$ Nanophosphors: Structural and Luminescence Properties. Proc. World Congr. New Technol. 2015, 7, 360-365.

23. Liu, Q.; Wang, L.; Wang, C.; Qu, W.; Tian, Z.; Ma, H.; Wang, D.; Wang, B.; Xu, Z. The effect of lanthanum doping on activity of $\mathrm{Zn}-\mathrm{Al}$ spinel for transesterification. Appl. Catal. B Environ. 2013, 136, 210-217. [CrossRef]

24. Rani, G.N.; Ayachit, N.H.; Nath, K.R.; Rao, V.J. Preparation and characterization of $\mathrm{Eu}^{3+}$ doped powder spinel phosphors $\left(\mathrm{MgAl}_{1.8} \mathrm{Y}_{0.2-\mathrm{x}} \mathrm{O}_{4}\right)$. Spectrochim. Acta A Mol. Biomol. Spectrosc. 2004, 60, 2481-2485. [CrossRef]

25. Wenisch, C.; Kurland, H.-D.; Grabow, J.; Müller, F.A. Europium(III)-Doped $\mathrm{MgAl}_{2} \mathrm{O}_{4}$ Spinel Nanophosphor Prepared by $\mathrm{CO}_{2}$ Laser Co-Vaporization. J. Am. Ceram. Soc. 2016, 99, 2561-2564. [CrossRef]

26. Boulon, G.; Alombert-Goget, G.; Guyot, Y.; Guzik, M.; Epicier, T.; Blanchard, N.P.; Chen, L.; Hu, L.; Chen, W. Conjugation of TEM-EDX and optical spectroscopy tools for the localization of $\mathrm{Yb}^{3+}, \mathrm{Er}^{3+}$ and $\mathrm{Co}^{2+}$ dopants in laser glass ceramics composed of $\mathrm{MgAl}_{2} \mathrm{O}_{4}$ spinel nano-crystals embedded in $\mathrm{SiO}_{2}$ glass. J. Mater Chem. C 2014, 2, 9385-9397. [CrossRef]

27. Gholami, A.; Maddahfar, M. Synthesis and characterization of novel samarium-doped $\mathrm{CuAl}_{2} \mathrm{O}_{4}$ and its photocatalytic performance through the modified sol-gel method. J. Mater. Sci. Mater. Electron. 2016, 27, 3341-3346. [CrossRef]

28. Choudhary, A.K.; Dwivedi, A.; Bahadur, A.; Rai, S.B. Effect of the concentration of the dopants $\left(\mathrm{Er}^{3+}\right.$, $\mathrm{Yb}^{3+}$ and $\mathrm{Zn}^{2+}$ ) and temperature on the upconversion emission behavior of $\mathrm{Er}^{3+} / \mathrm{Yb}^{3+}$ co-doped $\mathrm{SrAl}_{2} \mathrm{O}_{4}$ phosphor. Spectrochim. Acta A Mol. Biomol. Spectrosc. 2017, 185, 155-162. [CrossRef]

29. Lastovina, T.A.; Bugaev, A.L.; Kubrin, S.P.; Kudryavtsev, E.A.; Soldatov, A.V. Structural studies of magnetic nanoparticles doped with rare-earth elements. J. Struct. Chem. 2016, 57, 1444-1449. [CrossRef]

30. Akhtar, M.N.; Babar, M.; Qamar, S.; ur Rehman, Z.; Khan, M.A. Structural Rietveld refinement and magnetic features of prosademium (Pr) doped Cu nanocrystalline spinel ferrites. Ceram. Int. 2019, 45, 10187-10195. [CrossRef]

31. Ahmed, M.A.; Bishay, S.T.; Khafagy, R.M.; Saleh, N.M. Promising wastewater treatment using rare earth-doped nanoferrites. J. Magn. Magn. Mater. 2014, 350, 73-80. [CrossRef]

32. Chen, A.; Miyao, T.; Higashiyama, K.; Yamashita, H.; Watanabe, M. High Catalytic Performance of Ruthenium-Doped Mesoporous Nickel-Aluminum Oxides for Selective CO Methanation. Angew. Chem. Int. Ed. 2010, 49, 9895-9898. [CrossRef] [PubMed]

33. Farahani, M.D.; Dasireddy, V.D.B.C.; Friedrich, H.B. Oxidative Dehydrogenation of $n$-Octane over Niobium-Doped $\mathrm{NiAl}_{2} \mathrm{O}_{4}$ : An Example of Beneficial Coking in Catalysis over Spinel. ChemCatChem 2018, 10, 2059-2069. [CrossRef]

34. Akika, F.Z.; Benamira, M.; Lahmar, H.; Tibera, A.; Chabi, R.; Avramova, I.; Suzer, Ş.; Trari, M. Structural and optical properties of $\mathrm{Cu}$-substitution of $\mathrm{NiAl}_{2} \mathrm{O}_{4}$ and their photocatalytic activity towards Congo red under solar light irradiation. J. Photochem. Photobiol. Chem. 2018, 364, 542-550. [CrossRef]

35. Elakkiya, V.; Agarwal, Y.; Sumathi, S. Photocatalytic activity of divalent ion (copper, zinc and magnesium) doped $\mathrm{NiAl}_{2} \mathrm{O}_{4}$. Solid State Sci. 2018, 82, 92-98. [CrossRef]

36. Yu, L.; Song, M.; Williams, P.T.; Wei, Y. Alumina-Supported Spinel $\mathrm{NiAl}_{2} \mathrm{O}_{4}$ as a Catalyst for Re-forming Pyrolysis Gas. Ind. Eng. Chem. Res. 2019, 58, 11770-11778. [CrossRef]

37. Al Samarai, M.; Hahn, A.W.; Beheshti Askari, A.; Cui, Y.-T.; Yamazoe, K.; Miyawaki, J.; Harada, Y.; Rüdiger, O.; DeBeer, S. Elucidation of Structure-Activity Correlations in a Nickel Manganese Oxide Oxygen Evolution Reaction Catalyst by Operando Ni L-Edge X-ray Absorption Spectroscopy and 2p3d Resonant Inelastic X-ray Scattering. ACS Appl. Mater. Interfaces 2019, 11, 38595-38605. [CrossRef]

38. Ragupathi, C.; Vijaya, J.J.; Surendhar, P.; Kennedy, L.J. Comparative investigation of nickel aluminate $\left(\mathrm{NiAl}_{2} \mathrm{O}_{4}\right)$ nano and microstructures for the structural, optical and catalytic properties. Polyhedron 2014, 72, 1-7. [CrossRef] 
39. Sebai, I.; Salhi, N.; Rekhila, G.; Trari, M. Visible light induced $\mathrm{H}_{2}$ evolution on the spinel $\mathrm{NiAl}_{2} \mathrm{O}_{4}$ prepared by nitrate route. Int. J. Hydrog. Energy 2017, 42, 26652-26658. [CrossRef]

40. Menon, S.G.; Swart, H.C. Microwave-assisted synthesis of blue-green $\mathrm{NiAl}_{2} \mathrm{O}_{4}$ nanoparticle pigments with high near-infrared reflectance for indoor cooling. J. Alloys Compd. 2020, 819, 152991. [CrossRef]

41. López-Fonseca, R.; Jiménez-González, C.; de Rivas, B.; Gutiérrez-Ortiz, J.I. Partial oxidation of methane to syngas on bulk $\mathrm{NiAl}_{2} \mathrm{O}_{4}$ catalyst. Comparison with alumina supported nickel, platinum and rhodium catalysts. Appl. Catal. Gen. 2012, 437, 53-62. [CrossRef]

42. Li, Z.; Meng, X.; Zhang, Z. Fabrication of surface hydroxyl modified g- $\mathrm{C}_{3} \mathrm{~N}_{4}$ with enhanced photocatalytic oxidation activity. Catal. Sci. Technol. 2019, 9, 3979-3993. [CrossRef]

43. Villa, K.; Murcia-López, S.; Andreu, T.; Morante, J.R. On the role of $\mathrm{WO}_{3}$ surface hydroxyl groups for the photocatalytic partial oxidation of methane to methanol. Catal. Commun. 2015, 58, 200-203. [CrossRef]

44. Ooshiro, M.; Kobayashi, T.; Uchida, S. Compact Storage of Radioactive Cesium in Compressed Pellets of Zeolite Polymer Composite Fibers. Materials 2018, 11, 1347. [CrossRef] [PubMed]

45. Ge, D.-L.; Fan, Y.-J.; Qi, C.-L.; Sun, Z.-X. Facile synthesis of highly thermostable mesoporous $\mathrm{ZnAl}_{2} \mathrm{O}_{4}$ with adjustable pore size. J. Mater. Chem. A 2013, 1, 1651-1658. [CrossRef]

46. Jayasree, S.; Manikandan, A.; Arul Antony, S.; Uduman Mohideen, A.M.; Barathiraja, C. Magneto-Optical and Catalytic Properties of Recyclable Spinel $\mathrm{NiAl}_{2} \mathrm{O}_{4}$ Nanostructures Using Facile Combustion Methods. J. Supercond. Nov. Magn. 2016, 29, 253-263. [CrossRef]

47. Tangcharoen, T.; T-Thienprasert, J.; Kongmark, C. Effect of calcination temperature on structural and optical properties of $\mathrm{MAl}_{2} \mathrm{O}_{4}(\mathrm{M}=\mathrm{Ni}, \mathrm{Cu}, \mathrm{Zn})$ aluminate spinel nanoparticles. J. Adv. Ceram. 2019, 8, 352-366. [CrossRef]

48. Shannon, R.D. Revised effective ionic radii and systematic studies of interatomic distances in halides and chalcogenides. Acta Crystallogr. Sect. A 1976, 32, 751-767. [CrossRef]

49. Wiglusz, R.J.; Grzyb, T.; Bednarkiewicz, A.; Lis, S.; Strek, W. Investigation of Structure, Morphology, and Luminescence Properties in Blue-Red Emitter, Europium-Activated $\mathrm{ZnAl}_{2} \mathrm{O}_{4}$ Nanospinels. Eur. J. Inorg. Chem. 2012, 2012, 3418-3426. [CrossRef]

50. Dimitrievska, M.; Ivetić, T.B.; Litvinchuk, A.P.; Fairbrother, A.; Miljević, B.B.; Štrbac, G.R.; Pérez Rodríguez, A.; Lukić-Petrović, S.R. Eu ${ }^{3+}$-Doped Wide Band Gap $\mathrm{Zn}_{2} \mathrm{SnO}_{4}$ Semiconductor Nanoparticles: Structure and Luminescence. J. Phys. Chem. C 2016, 120, 18887-18894. [CrossRef]

51. Neilsen, G.; Rosen, P.F.; Dickson, M.S.; Popovic, M.; Schliesser, J.; Hansen, L.D.; Navrotsky, A.; Woodfield, B.F. Quantifying oxygen vacancies in neodymium and samarium doped ceria from heat capacity measurements. Acta Mater. 2020, 188, 740-744. [CrossRef]

(C) 2020 by the authors. Licensee MDPI, Basel, Switzerland. This article is an open access article distributed under the terms and conditions of the Creative Commons Attribution (CC BY) license (http://creativecommons.org/licenses/by/4.0/). 